\title{
A genome-wide scan of symptom dimensions in bipolar disorder pedigrees of adult probands
}

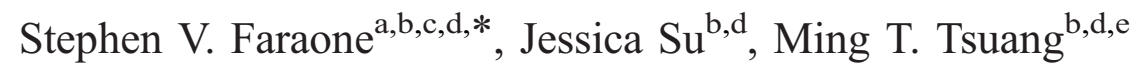 \\ ${ }^{a}$ Department of Psychiatry, Harvard Medical School, Massachusetts General Hospital, Boston, MA, United States \\ ${ }^{\mathrm{b}}$ Harvard Institute of Psychiatric Epidemiology and Genetics, Boston, MA, United States \\ ${ }^{\mathrm{c}}$ Johnson and Johnson Center for Pediatric Psychopathology at the Massachusetts General Hospital, WRN 705, 55 Fruit Street, Boston, \\ MA 02114-3139, United States \\ ${ }^{\mathrm{d}}$ Department of Epidemiology, Harvard School of Public Health, Boston, MA, United States \\ ${ }^{\mathrm{e}}$ Department of Psychiatry, University of California, San Diego, CA, United States
}

Received 10 October 2003; accepted 17 May 2004

\begin{abstract}
Although twin and adoption show bipolar disorder (BP) has a strong genetic component, few chromosomal regions have been consistently implicated by molecular genetic studies. To address this issue, we sought to determine if quantitative dimensions of bipolar disorder symptoms would be useful for detecting genes that underlie the susceptibility to bipolar disorder. Subjects were 520 individuals diagnosed with bipolar I, bipolar II or schizoaffective disorder, bipolar type who had participated in the NIMH genetics initiative for bipolar disorder. We constructed symptom scores from 29 psychiatric symptoms recorded in the Diagnostic Interview for Genetic Studies (DIGS). Principal components factor analysis followed by a varimax rotation was used to extract symptom dimensions. Factor scores were calculated for all genotyped individuals in the sample, regardless of affection status. Heritable factors were used in a variance-components linkage analysis, which utilized the exact likelihoods of allele-sharing identical-by-descent for each pair of relatives within each pedigree. The principal components factor analysis resulted in five independent dimensions: depressed state, psychosis, sleep disturbances, psychomotor acceleration, and irritability. Two factors were significantly heritable: depression $\left(h^{2}=0.53, p<0.001\right)$ and irritable vs. euphoric mania $\left(h^{2}=0.35, p=0.03\right)$. These were subsequently used in a linkage analysis that resulted in LOD scores of $<2.0$, which are not statistically significant. The five constructs developed through factor analysis appear to be consistent with previous factor analyses. Notably, only the dimensions associated with the type of mood disturbance showed high heritability, which suggests that careful measurements of depression, euphoria and irritability may be particularly useful in clarifying the genetic etiology of bipolar disorder in future studies.
\end{abstract}

(C) 2004 Elsevier B.V. All rights reserved.

Keywords: Symptom dimensions; Bipolar disorder; Linkage analysis

* Corresponding author. Pediatric Psychopharmacology Research, Massachusetts General Hospital, WRN 705, 55 Fruit Street, Boston, MA, United States. Tel.: +1 617726 2724; fax: +1 6177241540 .

E-mail address: sfaraone@hms.harvard.edu (S.V. Faraone).

0165-0327/\$ - see front matter (C) 2004 Elsevier B.V. All rights reserved.

doi:10.1016/j.jad.2004.05.015 


\section{Introduction}

A genetic basis of bipolar disorder (BP) has been firmly established with heritability estimates near $80 \%$ (Kendler et al., 1995). Monozygotic twins consistently show a greater risk for BP than dizygotic twins (Kendler et al., 1993; Torgersen, 1986) and adoption studies consistently show a greater risk of disease development in biological relatives (Mendlewicz and Rainer, 1977; Wender et al., 1986). Despite evidence that BP has a strong genetic component, few genes have been consistently implicated in the disease, leaving the genetic etiology largely unknown (Berrettini, 2001; Tsuang and Faraone, 2000).

Not only have individual findings been difficult to replicate, but also meta-analytic techniques have not conclusively identified BP susceptibility genes. Badner and Gershon (2002) used 1128 affected individuals from 11 studies and found the strongest evidence for linkage on chromosomes $13 \mathrm{q}$ and 22q. Another meta-analysis of 18 genome scans found no region that achieved genome-wide statistical significance (Segurado et al., 2003). The chromosomal regions that were identified in this analysis as most promising did not include chromosomes 13q or 22q.

Difficulty in gene identification has been attributed to diagnostic differences, complex genetics, and etiologic heterogeneity (Faraone et al., 1999; Risch and Botstein, 1996). Another reason for the slow progress towards gene identification may be the limitations of using categorical diagnostic systems to identify genetically homogeneous bipolar disorder subgroups. Although a positive diagnosis for bipolar disorder has high sensitivity and specificity for mental disorders in general, differentiating BP from disorders with overlapping characteristics is more difficult (Faraone et al., 1996). In families of bipolar disorder patients, symptoms of cyclothymia, dysthymia, depression, and hypomania do not always fit neatly into standard diagnostic formulations. Such complications point to the potential of alternate phenotype definitions in genetic analysis. For example, the age at onset of bipolar disorder may distinguish subforms of the disorder (Faraone et al., 2003) and a linkage analysis of age at onset identified potential susceptibility loci not identified in linkage studies of bipolar disorder (Faraone et al., submitted for publication).
Creating quantitative phenotypes of bipolar disorder symptom dimensions is one strategy for alternate phenotype definition. Several studies have used factor analysis to derive symptom dimensions for bipolar disorder. Most have used small samples in proportion to the number of variables analyzed (Akiskal et al., 2003; Akiskal et al., 2001; Benazzi and Akiskal, 2003; Dilsaver et al., 1999; Rossi et al., 2001; Swann et al., 2001; Ventura et al., 2000). Cassidy et al. (1998) studies 237 subjects having DSM III-R bipolar disorder. They found five factors: dysphoric mood, psychomotor pressure, psychosis, increased hedonic function, and irritable aggression. Serretti et al. (1999) studied 509 subjects having DSM III-R bipolar disorder. They found three factors: psychomotor acceleration, psychosis, and irritability. Sato et al. (2002) used 576 patients with 37 psychiatric conditions and found seven factors: depressive mood, irritable aggression, insomnia, depressive inhibition, pure psychomotor acceleration, emotional lability/ agitation, and psychosis. We utilized similar methodological techniques to identify underlying constructs of BP. We then performed linkage analysis on those constructs that were heritable to identify susceptibility genes for specific characteristics that are fundamental to BP.

These three studies suggest that, in large samples, reproducible dimensions of bipolar disorder symptoms can be identified. All three studies found dimensions reflecting psychosis, psychomotor acceleration, and irritability. Two of the three also extracted dysphoric mood as a symptom dimension. Given these findings, we sought to test three hypotheses: (1) that a factor analysis of the NIMH Genetics Initiative Bipolar Disorder data would yield similar dimensions; (2) that these dimensions would show evidence of heritability and (3) that quantitative trait linkage analysis would identify chromosomal regions harboring genes underlying these dimensions.

\section{Methods}

\subsection{Subjects}

Probands meeting DSM-III-R criteria for bipolar type 1 were systematically ascertained by screening consecutive patients at psychiatric hospitals near 
Indiana University, Johns Hopkins University, the NIMH Intramural Research program, and Washington University as part of the NIMH Human Genetics Initiative (http://www-srb.nimh.nih.gov/gi.html). If a case had at least one first degree relative with BP I (BPI) or schizoaffective disorder, bipolar type (SA/ BP), the family was retained for further examination. Families were excluded if both parents had either BPI or SA/BP. Subjects we separated into six diagnostic categories: BPI, BP II (BPII), SA/BP, unipolar depressed, other mental illness, and not mentally ill. BPI and SA/BP were established according to DSM III-R criteria while BPII and unipolar depressed were diagnosed according to RDC criteria. The overall sample consisted of 540 genotyped individuals in 97 families with $232 \mathrm{BPI}$, 32 SA/BP, 72 BPII, and 88 unipolar depressed individuals. A genome scan of these families with a qualitative trait for affection has been published elsewhere (Edenberg et al., 1997; Rice et al., 1997; Stine et al., 1997). We accessed the genotypes and clinical data through the NIMH Center for Genetic Studies (http://www.zork.wustl.edu/nimh/).

The Diagnostic Interview for Genetic Studies (DIGS) is a structured clinical interview that assesses the psychopathology of individuals. Among other sections the DIGS includes a detailed assessment of major depression, mania/hypomania, psychosis, drug abuse and dependence, suicidal behaviors, and anxiety disorders. Within-site and between-site test-retest reliabilities of DIGS-based diagnoses were evaluated according to DSM-III-R criteria for major depression, BP, schizophrenia, and schizoaffective disorder. Reliabilities were shown to be excellent (0.73-0.95) for all disorders except schizoaffective disorder, however, the bipolar and depressed subtype had a good specificity (Faraone et al., 1996; Nurnberger et al., 1994). A semi-structured itemized assessment of psychopathology in family members, the Family Instrument for Genetic Studies (FIGS), and medical records were used to supplement the DIGS data.

\subsection{Factor analysis}

There were 520 affected individuals included in the factor analysis: 369 (71.0\%) BPI, 115 (22.1\%) BPII, and $36(6.9 \%)$ SA/BP. A descriptive summary of these individuals is included in Table 1.
Table 1

Description of data used in factor analysis and linkage analysis

\begin{tabular}{|c|c|c|}
\hline & Factor analysis ${ }^{\mathrm{a}}$ & Linkage analysis $^{\mathrm{b}}$ \\
\hline Total & 520 & 206 \\
\hline \# Male (\%) & $216(41.5)$ & $81(39.3)$ \\
\hline \# Female $(\%)$ & $304(58.5)$ & $125(60.7)$ \\
\hline Number of families & 153 & 83 \\
\hline Age at interview (S.D.) & 47.8 (17.2) $n=512$ & $50.4(17.4)$ \\
\hline \multicolumn{3}{|l|}{ Age at onset } \\
\hline Depression (S.D.) & $21.5(10.0) n=466$ & $24.4(13.0) n=126$ \\
\hline Mania (S.D.) & $32.3(12.3) n=466$ & $32.4(13.3) n=77$ \\
\hline
\end{tabular}

A total of 29 psychiatric signs and symptoms relevant to BP were derived from data in the DIGS. These were: activity change, anxiety, aggression, anxiety, appetite change, distractibility, depressed mood, elation, fatigue, feeling of guilt, flight of ideas, grandiosity, hallucination, inadequacy, increased activity, inhibited thought, initial insomnia, irritability, lack of insight, loss of interest, middle insomnia, motor restlessness, persecutory delusions, psychomotor inhibition, racing thoughts, risky behavior, ruination, suicide, terminal insomnia, untrue beliefs, and weight change.

These symptoms were used in a principle components factor analysis followed by an orthogonal varimax rotation (Gorsuch, 1983). The number of factors in the final solution was determined by considering the scree plot, the proportion of the total variance explained, and the eigenvalue for the factor (must be greater than unity). Standardized factor scores were then calculated for all affected individuals and their family members. Unaffected family members did not contribute to the factor analysis but we generated factor scores for affected and unaffected individuals for genetic analysis. These analyses used SAS, version 8.1 (SAS, 2000).

\subsection{Genotyping and linkage analysis}

Genotyping methods have been described elsewhere (Edenberg et al., 1997; Rice et al., 1997; Stine et al., 1997). Allele frequencies were created previously using the program USER13, which uses maximum likelihood methods (Boehnke, 1991). Marker distances were created using CRIMAP and 
these results were compared to existing genetic databases. Mendelian inconsistencies were also examined previously. In total, there were 319 markers with an average interval spacing of $10 \mathrm{~cm}$ throughout the genome.

Each factor was assessed to insure that the distributional requirements of variance-components linkage analysis program, Sequential Oligogenic Linkage Analysis Routines (SOLAR) (Almasy and Blangero, 1998), were satisfied. Blangero et al. (2001) indicate that linkage analysis is appropriate using SOLAR if the following conditions are met: (1) the quantitative trait data resemble a normal distribution;

(2) the kurtosis of the distribution is less than 2.0; and (3) the $t$-test option is specified in SOLAR. When these assumptions were not met, rank transformations were employed.

The heritability of each factor score was calculated using SOLAR. Statistical modeling was employed to maximize the heritability of each factor by using the other factors as covariates. Factors with statistically significant ( $\alpha=0.05$ ) heritability estimates were used in the linkage analyses. Exact identity-by-descent (IBD) sharing proportions were calculated for each relative-pair within each pedigree using Genehunter 2.0 (Kruglyak et al., 1996). These IBD estimates were then transported into SOLAR and variance-components linkage analysis was performed on the heritable factor scores. LOD scores were calculated throughout the autosomal chromosomes at $2 \mathrm{~cm}$ intervals. Regions that had evidence for linkage (LOD $>0.5$ ) were fine-mapped with points at approximately $1 \mathrm{~cm}$ intervals. Table 1 shown above describes the basic demographics of individuals used in the genetic analyses.

\section{Results}

Five factors had eigenvalues greater than one and the scree plot indicated that a five-factor solution was appropriate. This solution explained $90.1 \%$ of the variance. For each symptom, Table 2 shows factor loadings greater than 0.30 along with the eigenvalues and percent variance explained for each factor. Of 29 symptoms, 24 loaded onto only one of the five factors. The symptom activity change loaded onto to 2 factors. Four symptoms, anxiety, obsessive/compulsive ten-
Table 2

Factor analysis summary of 520 individuals diagnosed with BPI, BPII, and SA/BP

\begin{tabular}{|c|c|c|c|c|c|}
\hline \multirow{2}{*}{$\begin{array}{l}\text { Psychiatric } \\
\text { sign/symptom }\end{array}$} & \multicolumn{5}{|c|}{ Factor loadings } \\
\hline & Factor 1 & Factor 2 & Factor 3 & Factor 4 & Factor 5 \\
\hline Depressed mood & 0.81 & & & & \\
\hline Loss of interest & 0.79 & & & & \\
\hline Inhibited thought & 0.67 & & & & \\
\hline Inadequacy & 0.61 & & & & \\
\hline Feeling of guilt & 0.60 & & & & \\
\hline Fatigue & 0.60 & & & & \\
\hline $\begin{array}{l}\text { Psychomotor } \\
\text { inhibition }\end{array}$ & 0.53 & & & & \\
\hline Activity change & 0.53 & & & 0.50 & \\
\hline Appetite change & 0.51 & & & & \\
\hline Weight change & 0.50 & & & & \\
\hline Suicide & 0.42 & & & & \\
\hline $\begin{array}{l}\text { Persecutory } \\
\text { delusions }\end{array}$ & & 0.76 & & & \\
\hline Untrue beliefs & & 0.71 & & & \\
\hline Hallucinations & & 0.71 & & & \\
\hline Grandiosity & & 0.67 & & & \\
\hline Middle insomnia & & & 0.76 & & \\
\hline Terminal insomnia & & & 0.71 & & \\
\hline Initial insomnia & & & 0.61 & & \\
\hline Motor restlessness & & & 0.52 & & \\
\hline Flight of ideas & & & & 0.75 & \\
\hline Distractibility & & & & 0.67 & \\
\hline Racing thoughts & & & & 0.37 & \\
\hline Increased activities & & & & 0.31 & \\
\hline Irritability & & & & & 0.71 \\
\hline Elation & & & & & -0.61 \\
\hline Eigenvalues & 5.32 & 2.77 & 1.64 & 1.25 & 1.1 \\
\hline $\begin{array}{l}\text { Proportion } \\
\text { variance } \\
\text { explained }\end{array}$ & 0.400 & 0.208 & 0.123 & 0.094 & 0.083 \\
\hline $\begin{array}{l}\text { Cumulative } \\
\text { variance }\end{array}$ & 0.400 & 0.608 & 0.732 & 0.826 & 0.909 \\
\hline
\end{tabular}

dencies, aggression, and lack of insight did not load onto any factor.

The first factor reflects depressed state. It includes depression, loss of interest, inhibited thought, inadequacy, feelings of guilt, fatigue, psychomotor inhibition, activity change, appetite change, weight change, and suicide. Factor two describes psychosis with high loadings for persecutory delusions, untrue beliefs, hallucinations, and grandiosity. Factor three comprises sleep disturbances, which includes initial, mid, and terminal insomnia as well as motor restlessness. The fourth factor describes psychomotor acceleration such as flight of ideas, distractibility, racing thoughts, and 
increased activity. Factor five differentiates irritable and euphoric mania with a large positive loading for irritability and a strong negative loading for elation. Aggression was also associated with this factor (i.e. the highest loading for aggression was this factor), however the factor loading was not large $(0.24)$.

All five factors were highly non-normal and therefore were transformed using a rank transformation. Two of the five factor scores were significantly heritable and subsequently used in linkage analysis. The heritability for depression was $0.53\left(\mathrm{se}\left(h^{2}\right)=0.16\right.$, $p<0.001)$ in a model that incorporated three other factors as covariates: psychosis $(p=0.003)$; sleep disturbance $(p=0.07)$; and mania type $(p<0.001)$. The model examining irritable vs. euphoric mania was also significantly heritable $\left(h^{2}=0.35, \operatorname{se}\left(h^{2}\right)=0.19\right.$, $p<0.03)$ and used depression, sleep disturbances, and psychomotor acceleration as covariates $(p<$ $0.001, p=0.001, p=0.004$, respectively). Psychosis, sleep disturbance, and psychomotor acceleration did not yield significant heritabilities.

The strongest results of the genome screen for the depression and irritable vs. euphoric mania factors are presented in Fig. 1. No chromosomal region reached the established threshold of statistical significance (Lander and Kruglyak, 1995). For the depression factor, the highest LOD score was 1.38 on chromosome 1 at $107 \mathrm{~cm}$, located between markers D1S224 and D1S1648. One region on chromosome 2 also achieved a LOD score greater than 1.0. The irritable vs. euphoric factor had a peak LOD score of 1.47 on chromosome 5 at $130 \mathrm{~cm}$, closest to marker D5S1549, with LOD scores in regions on chromosomes 2,14 , and 18 also achieving values greater than 1.0 .

\section{Discussion}

Our work suggests that there are five domains underlying BP: depression, psychosis, sleep disturbance, psychomotor acceleration, and irritability. Overall, these findings largely agree with previously published studies. A depression factor had been identified in several studies of individuals with bipolar disorder (Cassidy et al., 1998; Dilsaver et al., 1999; Rossi et al., 2001; Sato et al., 2002). Although one study (Sato et al., 2002) differentiated depressive inhibition from depressed mood, our findings did not. Our psychosis factor encompasses classic psychotic symptoms including persecutory delusion, grandiosity, untrue beliefs, and hallucination. This findings replicates other research that identified psychosis as a factor independent of the core manic and depressive symptoms (Cassidy et al., 1998; Sato et al., 2002).

Our sleep disturbance factor has also been seen in three previous reports (Dilsaver et al., 1999; Rossi et al., 2001; Sato et al., 2002). There is therefore an accumulating body of evidence to suggest that sleep disturbance acts as an independently of other aspects of disease, such as manic, depressive, and psychotic symptoms. Our fourth factor describes the psychomotor acceleration common in manic episodes. It included flight of ideas, distractibility, racing thoughts, and increased activity. This factor resembles several factors from previous research (Cassidy et al.,
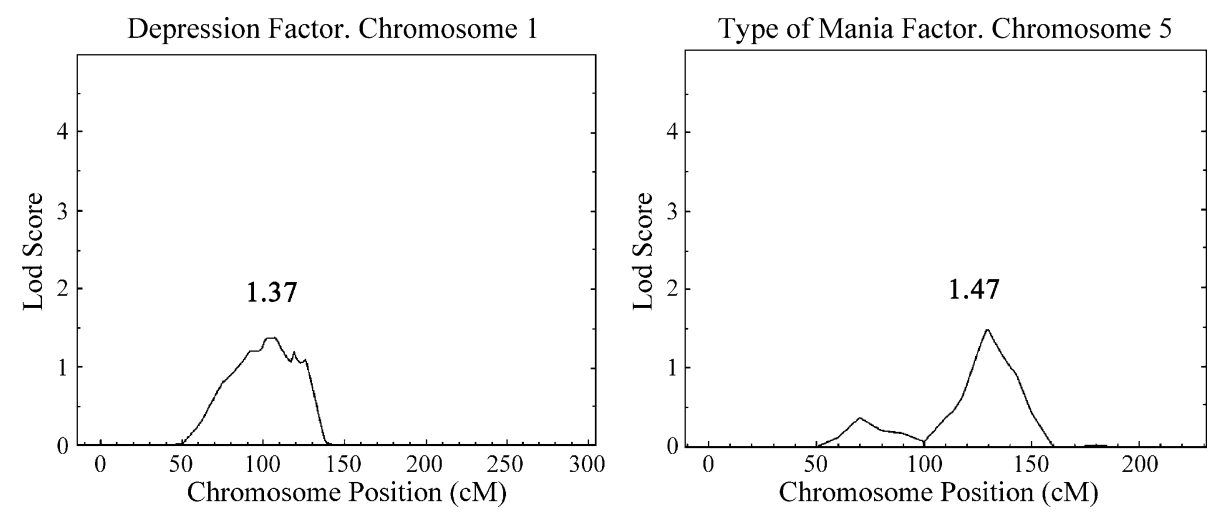

Fig. 1. The strongest evidence for linkage with the depression and type of mania factors. 
1998; Dilsaver et al., 1999; Rossi et al., 2001; Sato et al., 2002; Serretti et al., 1999). The variable activity change loaded onto this factor as well as factor1, the depressive factor. This makes intuitive sense, as this variable identifies a change in activity and not the direction of the change. Therefore one would expect that activity change would occur during both mania and depression, with increasing and decreasing levels, respectively. Our study concurs with this expectation, as activity change has equal loadings on both factors.

Previous studies have also identified an irritable aggression factor similar to our factor five, although in prior studies aggression loaded higher that it did in our analysis (Cassidy et al., 1998; Dilsaver et al., 1999; Sato et al., 2002; Serretti et al., 1999). Although aggression did not load as strongly as in other studies, the variable had the highest loading on this factor (0.24), indicating that the aggressive irritability factor that has been identified previously concurs with these findings. In summary, the symptom dimensions extracted from our factor analysis substantially overlap with studies previously reported in the literature. Similar to past work, we obtained independent atypical features of depression, insomnia, psychosis, and irritability. Thus, it is likely that these symptom dimensions will be useful for future studies of bipolar disorder.

Only the depressive and irritable vs. euphoric mania factors were significantly heritable, while controlling for the other significant factors as covariates in the polygenic model. The heritability estimates were 0.53 and 0.35 for depressive symptoms and irritable vs. euphoric mania, respectively, suggesting that genes are likely to be acting in each of these domains. In future genetic studies, it may therefore be useful to utilize more detailed data related to these constructs to further efforts towards gene identification for bipolar disorder. Such genes may not only influence bipolar disorder, but may also play a role in other mental illnesses with depressive and irritable characteristics. We did not identify insomnia, psychomotor acceleration, or psychosis as being heritable. This may indicate that although some of these constructs are heritable for other disorders (i.e. psychosis in schizophrenia), they may not be heritable for bipolar disorder families.

Our linkage analysis of the two heritable traits found little evidence for linkage, as none of the chromosomal regions reached statistical significance. The strongest findings showed only weak evidence for linkage to regions of chromosome 1 , at $107 \mathrm{~cm}$, for the depression factor and chromosome 5, at $130 \mathrm{~cm}$, for the irritable vs. euphoric mania factor. Nevertheless, it is worth considering how these locations fit with prior linkage studies of bipolar disorder. Blackwood et al. (1996) reported a positive finding in the chromosome 1 region. The meta-analysis by Segurado et al. (2003) shows that this study had a positive finding in the same bin as our finding on chromosome 1. This linkage region had also been implicated by the initial genome scan from the NIMH Genetics Initiative Bipolar Consortium using a narrow definition of bipolar disorder (Rice et al., 1997).

No prior studies of bipolar disorder have implicated the region of chromosome 5 that showed weak evidence of linkage in our analysis of the irritable vs. euphoric mania factor. The lack of prior findings suggests this finding may be a false positive. But it is also possible we have found a region that is specific to the irritability-euphoria dimension. Albeit intriguing, our findings must be interpreted cautiously as neither quantitative trait achieved the threshold for significant linkage in any region of the genome. Our results also show no evidence of linkage to the most promising chromosomal regions identified in meta analyses of bipolar disorder: 8p, 9p, 10q, 13q, 14q, and 22q (Badner and Gershon, 2002; Segurado et al., 2003). Nor did our findings detect the regions implicated by the most recent and largest genome scan of bipolar disorder to date: 6q and 17q (Dick et al., 2003).

There are several limitations to this study that should be considered. Factor scores can only be generated for individuals with complete data. We had clinical information on 520 individuals, but only 206 had complete data and were subsequently given factor scores. This smaller sample size limited our power to detect genes with linkage analysis. Also, the DIGS interview not designed explicitly for creating quantitative bipolar disorder symptom dimensions. It is likely that a study designed to collect quantitative trait data would create factor scores with less measurement error and higher heritabilities.

Despite these limitations, we identified five symptom dimensions through a factor analysis that may be useful for future studies: depressive symptoms, psychosis, insomnia, psychomotor acceleration, and 
irritability. Two of these, depressive symptoms and irritability, were heritable and may be useful in future molecular genetic research.

\section{Acknowledgements}

The linkage analysis and manuscript preparation was supported in part by National Institutes of Health grants R01MH57934, R01HD37694, R13MH59126 (Dr. Faraone, PI) and R01MH43518, R01MH59624 and R01MH60485 (Dr. Tsuang, PI) and by grants from the Stanley Foundation (J. Biederman, PI) and Johnson and Johnson (J. Biederman, PI).

The clinical data and genotypes were provided by the NIMH Genetics Initiative Data Repository. The clinical data were collected at four sites: Indiana University, Johns Hopkins University, NIMH Intramural Research program, and Washington University. The principal investigators at these sites were $\mathrm{J}$. Nurnberger, J. DePaulo, E. Gershon, and T. Reich, respectively. The lead NIMH investigator was $\mathrm{M}$. Blehar. The genotypes were generated in the laboratories of: A. Goate, PhD, Department of Psychiatry, Washington University School of Medicine; H. Edenberg, PhD, Indiana University School of Medicine, S. Detera-Wadleigh, NIMH Intramural Research Program and O. Stine, Johns Hopkins University School of Medicine.

\section{References}

Akiskal, H.S., Hantouche, E.G., Bourgeois, M.L., Azorin, J.M., Sechter, D., Allilaire, J.F., Chatenet-Duchene, L., Lancrenon, S., 2001. Toward a refined phenomenology of mania: combining clinician-assessment and self-report in the French EPIMAN study. J. Affect. Disord. 67, 89-96.

Akiskal, H.S., Azorin, J.M., Hantouche, E.G., 2003. Proposed multidimensional structure of mania: beyond the euphoricdysphoric dichotomy. J. Affect. Disord. 73, 7-18.

Almasy, L., Blangero, J., 1998. Multipoint quantitative-trait linkage analysis in general pedigrees. Am. J. Hum. Genet. 62, $1198-1211$.

Badner, J., Gershon, E., 2002. Meta-analysis of whole-genome linkage scans of bipolar disorder and schizophrenia. Mol. Psychiatry 7, 405-411.

Benazzi, F., Akiskal, H.S., 2003. The dual factor structure of selfrated MDQ hypomania: energized-activity versus irritablethought racing. J. Affect. Disord. 73, 59-64.
Berrettini, W.H., 2001. Molecular linkage studies of bipolar disorders. Bipolar Disord. 3, 276-283.

Blackwood, D.H.R., He, L., Morris, S.W., McLean, A., Whitton, C., Thomson, M., Walker, M.T., Woodburn, K., Sharp, C.M., Wright, A.F., Shibasaki, Y., St. Clair, D.M., Porteous, D.J., Muir, W.J., 1996. A locus for bipolar affective disorder on chromosome 4p. Nat. Genet. 12, 427-430.

Blangero, J., Williams, J., Almasy, 1., 2001. Variance component methods for detecting complex trait loci. Adv. Genet. 42, $151-181$.

Boehnke, M., 1991. Allele frequency estimation from data on relatives. Am. J. Hum. Genet. 48, 22-25.

Cassidy, F., Forest, K., Murry, E., Carroll, B.J., 1998. Original article a factor analysis of the signs and symptoms of mania. Arch. Gen. Psychiatry 55, 27-32.

Dick, D.M., Foroud, T., Flury, L., Bowman, E.S., Miller, M.J., Rau, N.L., Moe, P.R., Samavedy, N., El-Mallakh, R., Manji, H., Glitz, D.A., Meyer, E.T., Smiley, C., Hahn, R., Widmark, C., McKinney, R., Sutton, L., Ballas, C., Grice, D., Berrettini, W., Byerley, W., Coryell, W., DePaulo, R., MacKinnon, D.F., Gershon, E.S., Kelsoe, J.R., McMahon, F.J., McInnis, M., Murphy, D.L., Reich, T., Scheftner, W., Nurnberger Jr., J.I., 2003. Genomewide linkage analyses of bipolar disorder: a new sample of 250 pedigrees from the national institute of mental health genetics initiative. Am. J. Hum. Genet. 73, 107-114.

Dilsaver, S.C., Chen, Y.R., Shoaib, A.M., Swann, A.C., 1999. Phenomenology of mania: evidence for distinct depressed, dysphoric, and euphoric presentations. Am. J. Psychiatry 156, 426-430.

Edenberg, H.J., Foroud, T., Conneally, P.M., Sorbel, J.J., Carr, K., Crose, C., Willig, C., Zhao, J., Miller, M., Bowman, E., Mayeda, A., Rau, N.L., Smiley, C., Rice, J.P., Goate, A., Reich, T., Stine, O.C., McMahon, F., DePaulo, J.R., Meyers, D., Detera-Wadleigh, S.D., Goldin, L.R., Gershon, E.S., Blehar, M.C., Nurnberger Jr., J.I., 1997. Initial genomic scan of the NIMH genetics initiative bipolar pedigrees: chromosomes 3, 5, 15, 16, 17, and 22. Am. J. Med. Genet. (Neuropsychiat Genet) 74, 238-246.

Faraone, S.V., Blehar, M., Pepple, J., Moldin, S., Norton, J., Tsuang, M.T., Nurnberger, J.I., Malaspina, D., Kaufmann, C.A., Reich, T., Cloninger, C.R., DePaulo, J.R., Berg, K., Gershon, E.S., Kirch, D.G., Tsuang, M.T., 1996. Diagnostic accuracy and confusability analyses: an application to the diagnostic interview for genetic studies. Psychol. Med. 26, 401-410.

Faraone, S.V., Tsuang, D., Tsuang, M.T., 1999. Genetics of Mental Disorders: A Guide for Students, Clinicians, and Researchers. Guilford, New York, NY.

Faraone, S.V., Glatt, S.J., Tsuang, M.T., 2003. The genetics of pediatric-onset bipolar disorder. Biol. Psychiatry 53, 970-977.

Faraone, S.V., Glatt, S.J., Su, J., Tsuang, M.T. (submitted for publication), A Genome-Wide Scan of the Age at Onset of Mania Yields Three Potential Susceptibility Loci.

Gorsuch, R., 1983. Factor Analysis. Lawrence Erlbaum Associates, Hillsdale, NJ.

Kendler, K.S., Neale, M., Kessler, R., Heath, A., Eaves, L., 1993. A twin study of recent life events and difficulties. Arch. Gen. Psychiatry 50, 789-796. 
Kendler, K., Pedersen, N., Neale, M.A.M., 1995. A pilot Swedish twin study of affective illness including hospital- and population-ascertained subsamples: results of model fitting. Behav. Genet. 25, 217-232.

Kruglyak, L., Daly, M.J., Reeve-Daly, M.P., Lander, E.S., 1996. Parametric and nonparametric linkage analysis: a unified multipoint approach. Am. J. Hum. Genet. 58, 1347-1363.

Lander, E., Kruglyak, L., 1995. Genetic dissection of complex traits: guidelines for interpreting and reporting linkage results. Nat. Genet. 11, 241-247.

Mendlewicz, J., Rainer, J.D., 1977. Adoption study supporting genetic transmission in manic-depressive illness. Nature 268, $327-329$.

Nurnberger Jr., J.I., Blehar, M.C., Kaufmann, C.A., York-Cooler, C., Simpson, S.G., Harkavy-Friedman, J., Severe, J.B., Malaspina, D., Reich, T., Miller, M., Bowman, E.S., DePaulo, J.R., Cloninger, C.R., Robinson, G., Moldin, S., Gershon, E.S., Maxwell, E., Guroff, J.J., Kirch, D., Wynne, D., Berg, K., Tsuang, M.T., Faraone, S.V., Pepple, J.R., Ritz, A.L., 1994. Diagnostic interview for genetic studies. Rationale, unique features, and training. Arch. Gen. Psychiatry 51, 849-859.

Rice, J.P., Goate, A., Williams, J.T., Bierut, L., Dorr, D., Wu, W., Shears, S., Gopalakrishnan, G., Edenberg, H.J., Foroud, T., Nurnberger, J.J., Gershon, E.S., Detera-Wadleigh, S.D., Goldin, L.R., Guroff, J.J., McMahon, F.J., Simpson, S., MacKinnon, D., McInnis, M., Stine, O.C., DePaulo, J.R., Blehar, M.R., Reich, T., 1997. Initial genome scan of the NIMH genetics initiative bipolar pedigrees: chromosomes 1, 6, 8, 10, and 12. Am. J. Med. Genet. (Neuropsychiat Genet) 74, 247-253.

Risch, N., Botstein, D., 1996. A manic depressive history. Nat. Genet. 12, 351-353.

Rossi, A., Daneluzzo, E., Arduini, L., Di Domenico, M., Pollice, R., Petruzzi, C., 2001. A factor analysis of signs and symptoms of the manic episode with Bech-Rafaelsen mania and melancholia scales. J. Affect. Disord. 64, 267-270.

SAS (2000), Statistical Analysis System, Version 8.1. Cary, NC, SAS Institute.

Sato, T., Bottlender, R., Kleindienst, N., Moller, H.-J., 2002. Syndromes and phenomenological subtypes underlying acute mania: a factor analytic study of 576 manic patients. Am. J. Psychiatr. 159, 968-974.

Segurado, R., Detera-Wadleigh, S.D., Levinson, D.F., Lewis, C.M., Gill, M., Nurnberger Jr., J.I., Craddock, N., DePaulo, J.R., Baron, M., Gershon, E.S., Ekholm, J., Cichon, S., Turecki, G., Claes, S., Kelsoe, J.R., Schofield, P.R., Badenhop, R.F., Morissette, J., Coon, H., Blackwood, D., McInnes, L.A., Foroud, T., Edenberg, H.J., Reich, T., Rice, J.P., Goate, A.,
McInnis, M.G., McMahon, F.J., Badner, J.A., Goldin, L.R., Bennett, P., Willour, V.L., Zandi, P.P., Liu, J., Gilliam, C., Juo, S.H., Berrettini, W.H., Yoshikawa, T., Peltonen, L., Lonnqvist, J., Nothen, M.M., Schumacher, J., Windemuth, C., Rietschel, M., Propping, P., Maier, W., Alda, M., Grof, P., Rouleau, G.A., Del-Favero, J., Van Broeckhoven, C., Mendlewicz, J., Adolfsson, R., Spence, M.A., Luebbert, H., Adams, L.J., Donald, J.A., Mitchell, P.B., Barden, N., Shink, E., Byerley, W., Muir, W., Visscher, P.M., Macgregor, S., Gurling, H., Kalsi, G., McQuillin, A., Escamilla, M.A., Reus, V.I., Leon, P., Freimer, N.B., Ewald, H., Kruse, T.A., Mors, O., Radhakrishna, U., Blouin, J.L., Antonarakis, S.E., Akarsu, N., 2003. Genome scan metaanalysis of schizophrenia and bipolar disorder: Part III. Bipolar disorder. Am. J. Hum. Genet. 73, 49-62.

Serretti, A., Rietschel, M., Lattuada, E., Krauss, H., Held, T., Nothen, M.M., Smeraldi, E., 1999. Factor analysis of mania. Arch. Gen. Psychiatry 56, 671-672.

Stine, O.C., McMahon, F.J., Chen, L., Xu, J., Meyers, D.A., MacKinnon, D.F., Simpson, S., McInnis, M.G., Rice, J.P., Goate, A., Reich, T., Edenberg, H.J., Foroud, T., Nurnberger Jr., J.I., Detera-Wadleigh, S.D., Goldin, L.R., Guroff, J., Gershon, E.S., Blehar, M.C., DePaulo, J.R., 1997. Initial genome screen for bipolar disorder in the NIMH genetics initiative pedigrees: chromosomes 2, 11, 13, 14, and X. Am. J. Med. Genet. (Neuropsychiat Genet) 74, 263-269.

Swann, A.C., Janicak, P.L., Calabrese, J.R., Bowden, C.L., Dilsaver, S.C., Morris, D.D., Petty, F., Davis, J.M., 2001. Structure of mania: depressive, irritable, and psychotic clusters with different retrospectively-assessed course patterns of illness in randomized clinical trial participants. J. Affect. Disord. 67, $123-132$.

Torgersen, S., 1986. Genetic factors in moderately severe and mild affective disorders. Arch. Gen. Psychiatry 43, 222-226.

Tsuang, M.T., Faraone, S.V., 2000. The genetic epidemiology of bipolar disorder. In: Marneros, A., Angst, J. (Eds.), Bipolar Disorders: 100 Years After Manic-Depressive Insanity. Kluwer Academic, Zurich, pp. 231-242.

Ventura, J., Nuechterlein, K.H., Subotnik, K.L., Gutkind, D., Gilbert, E.A., 2000. Symptom dimensions in recent-onset schizophrenia and mania: a principal components analysis of the 24-item Brief Psychiatric Rating Scale. Psychiatry Res. 97, $129-135$.

Wender, P.H., Kety, S.S., Rosenthal, D., Schulsinger, F., Ortmann, J., Lunde, I., 1986. Psychiatric disorders in the biological and adoptive families of adopted individuals with affective disorders. Arch. Gen. Psychiatry 43, 923-929. 